\title{
Erratum to: Quantum well intermixed waveguide grating
}

\author{
Ramesh K. Sonkar • Utpal Das
}

Published online: 28 January 2012

(C) Springer Science+Business Media, LLC. 2012

\section{Erratum to: Opt Quant Electron (2011) 42:631-643 DOI 10.1007/s11082-011-9486-3}

The authors would like to correct the incorrect text and equations in the original publication of the article.

Paragraph 1 in the published article (in page 637) should read as "Band to band transition as well as excitonic effects was taken into consideration while calculating the dielectric constants."

The correct version of the Eqs. 12 and 13 is given in detail below

$$
\varepsilon_{2}^{Q W}(\omega)=\frac{C}{\omega^{2}} \sum_{m n}\left[m_{h h}\left|O_{m n}^{h}\right|^{2} \Theta\left(\hbar \omega-E_{m n}^{h h}\right)+\frac{m_{l h}}{3}\left|O_{m n}^{l}\right|^{2} \Theta\left(\hbar \omega-E_{i m n}^{l h}\right)\right]
$$

where $O_{m n}^{h}$ and $O_{m n}^{l}$ are the overlap integrals of $m^{t h}$ conduction band eigen function and $n^{t h} \mathrm{VB}$ eigen function for $\mathrm{HH}$ and $\mathrm{LH}$, respectively. With $C=\pi e^{2} P_{C V}^{2} / \hbar^{2} m_{0} W \varepsilon_{0}$. where, $P_{C V}^{2}=\left(2 / m_{0}\right)\left\langle s\left|p_{x}\right| x\right\rangle^{2}$ is a parameter related to the squared matrix element. $m_{h h}$ and $m_{l h}$ are the reduced electron-heavy hole and electron-light hole masses respectively.

$$
\begin{aligned}
\varepsilon_{1}(\omega)= & +\varepsilon_{b}+\frac{C}{\pi \omega^{2}} \sum_{m n}\left[m_{h h}\left|O_{m n}^{h}\right|^{2} \ln \left|\frac{\left(E_{m n}^{h h}\right)^{2}}{\left(E_{m n}^{h h}\right)^{2}-(\hbar \omega)^{2}}\right|\right. \\
& \left.+\frac{m_{l h}}{3}\left|O_{m n}^{l}\right|^{2} \ln \left|\frac{\left(E_{m n}^{l h}\right)^{2}}{\left(E_{m n}^{l h}\right)^{2}-(\hbar \omega)^{2}}\right|\right]
\end{aligned}
$$

The online version of the original article can be found under doi:10.1007/s11082-011-9486-3.

R. K. Sonkar $(\varangle) \cdot$ U. Das

Department of Electrical Engineering, Indian Institute of Technology, Kanpur, India e-mail: rksonkar@iitk.ac.in 